\title{
Ventricular restraint therapy for heart failure: A review, summary of state of the art, and future directions
}

\author{
Michael H. Kwon, MD, Marisa Cevasco, MD, MPH, Jan D. Schmitto, MD, PhD, and \\ Frederick Y. Chen, MD, PhD
}

\begin{abstract}
Congestive heart failure is a leading cause of death in developed countries, and its incidence is expected to increase in parallel with the aging population. Most current therapies for congestive heart failure lead to modest symptom relief but are unable to significantly improve long-term survival outcomes. Indeed, there is no effective treatment except cardiac transplantation, which remains epidemiologically insignificant because of donor pool limitations. New strategies for treating congestive heart failure are needed. Ventricular restraint is a promising, nontransplant surgical therapy in which the overall goal is to wrap the dilated, failing heart with prosthetic material to mechanically constrain the heart at enddiastole, prevent further remodeling, and thereby ultimately improve ventricular function, patient symptoms, and survival. In this review, the principles of cardiac restraint therapy will be discussed. An overview of 3 restraint devices, along with their specific advantages and disadvantages, will be presented. The existing peer-reviewed literature from both animal and human trials will be summarized with an emphasis on understanding the mechanism of restraint therapy and how this knowledge can be used to optimize and improve its efficacy. (J Thorac Cardiovasc Surg 2012;144:771-7)
\end{abstract}

\section{Supplemental material is available online.}

Congestive heart failure (CHF) affects approximately 6 million Americans and is the underlying cause of death in 55,000 patients annually. ${ }^{1}$ Current therapies, including medications and lifestyle changes, offer modest symptom relief but are unable to significantly improve long-term survival because they do little to prevent the progressive adverse remodeling of damaged myocardium in CHF.

Surgical interventions for CHF include coronary revascularization, valve repair or replacement, and biventricular pacing as appropriate. Alternative approaches, including surgical ventricular reconstruction (Dor procedure) and reduction left ventriculoplasty (Batista procedure), have demonstrated high mortality, minimal improvement in quality of life and ventricular function, and no survival benefit, ${ }^{\text {E1-E4 }}$ ultimately precluding their widespread clinical adoption. The Myosplint (Myocor Inc, Maple Grove, Minn), a transventricular girdle device that passively reduces left ventricular (LV) diameter, has variable impact on quality of life and unknown impact on survival. ${ }^{\text {E5 }}$ Left ventricular assist device (LVAD) therapy, used as destination therapy, bridge to transplantation, decision, or recovery, has proven benefit compared with medical therapy, ${ }^{\mathrm{E} 6-\mathrm{E} 9}$ but it is highly

\footnotetext{
From the Division of Cardiac Surgery, Department of Surgery, Brigham and Woman's Hospital, Harvard Medical School, Boston, Mass.

Disclosures: Authors have nothing to disclose with regard to commercial support.

Received for publication Jan 23, 2012; revisions received April 2, 2012; accepted for publication June 8, 2012; available ahead of print July 3, 2012.

Address for reprints: Frederick Y. Chen, MD, PhD, Division of Cardiac Surgery, Brigham and Women's Hospital, Harvard Medical School, 75 Francis St, Boston, MA 02115 (E-mail: fchen@partners.org).

$0022-5223 / \$ 36.00$

Copyright (c) 2012 by The American Association for Thoracic Surgery http://dx.doi.org/10.1016/j.jtcvs.2012.06.014
}

resource-intensive and remains associated with driveline infections and thromboembolism. The Anstadt cup is a pneumatic epicardial balloon device that provides systolic and diastolic augmentation and is known to improve cardiac function in animal models, ${ }^{\mathrm{E} 10}$ but the external driveline remains a major disadvantage. All told, current interventions often improve symptoms but have minimal impact on longterm outcomes except for heart transplantation, for which the epidemiologic impact remains limited by the donor pool. Alternative nontransplant surgical therapies for $\mathrm{CHF}$ are needed.

In the 1980s, Carpentier developed cardiomyoplasty, a procedure in which the heart was wrapped with a lastissimus dorsi muscle flap and stimulated to contract with systole. ${ }^{\text {E11 }}$ Although the procedure was effective at reducing myocardial oxygen consumption $\left(\mathrm{mVO}_{2}\right)$, wall stress, and adverse remodeling, ${ }^{2}$ these benefits persisted even if the muscle flap was not stimulated, that is, these effects remained with simply a passive muscle wrap. ${ }^{3}$ Passive prosthetic wraps were therefore developed, and ventricular restraint therapy was born.

Given that increased LV size and attendant increases in wall stress and $\mathrm{mVO}_{2}$ are associated with poor clinical outcomes in $\mathrm{CHF}$, the goal of restraint is to prosthetically wrap the dilated, failing heart to mechanically limit its size, thereby preventing and reversing the process of adverse remodeling while improving cardiac function and patient outcomes. There are currently 2 ventricular restraint devices studied in both animals and humans, including a woven textile device (CorCap; Acorn Cardiovascular Inc, St Paul, Minn) (Figure 1) ${ }^{4}$ and a Nitinol mesh device (HeartNet; Paracor Medical, Sunnyvale, Calif) (Figure 2). ${ }^{5}$ A polyurethane half-ellipsoid balloon device has been experimentally developed by our group (Polyzen, Inc, Apex, NC) (Figures 3 and 4). ${ }^{6}$ This review will summarize the mechanisms, clinical outcomes, and limitations of these devices, with 

Abbreviations and Acronyms
$\mathrm{CHF}=$ congestive heart failure
EDD = end-diastolic dimension
$\mathrm{EDP}=$ end-diastolic pressure
$\mathrm{EDV}=$ end-diastolic volume
$\mathrm{EF}=$ ejection fraction
$\mathrm{ESV}=$ end-systolic volume
FMR = functional mitral regurgitation
$\mathrm{LV}=$ left ventricular, left ventricle
LVAD $=$ left ventricular assist device
MMP = matrix metalloproteinase
$\mathrm{MR}=$ mitral regurgitation
$\mathrm{mVO}_{2}=$ myocardial oxygen consumption
MVR = mitral valve replacement
NYHA $=$ New York Heart Association
$\mathrm{P}_{\mathrm{tm}}=$ transmural myocardial pressure
QVR = quantitative ventricular restraint
$\mathrm{RV} \quad=$ right ventricular, right ventricle

an emphasis on how restraint therapy can be further optimized to improve efficacy.

\section{ACORN: CORCAP}

The Acorn CorCap Cardiac Support Device was the first and most extensively studied restraint device (Figure 1). It is composed of a flexible, polyethylene-terephthalate mesh that covers both ventricles, creating an absolute limit to the end-diastolic volume (EDV). It is placed via median sternotomy and secured with 8-10 polypropylene sutures circumferentially around the atrioventricular groove, after which excess mesh is excised and resewn to ensure a snug fit at end-diastole. ${ }^{7}$ The degree of tightness is adjusted to achieve approximately $5 \%$ reduction in the echocardiographic diameter of the heart. ${ }^{7}$

\section{Animal Studies}

Hemodynamic studies. In 1999, the first reported animal study of ventricular restraint demonstrated that prophylactic ventricular restraint is sufficient to attenuate the adverse functional and morphologic changes associated with postinfarction $\mathrm{CHF}^{8}$ Sheep that underwent placement of a Marlex (polypropylene) mesh restraint device before creation of a delayed anteroapical infarct via coronary snare occlusion had significantly lower LV end-diastolic pressure (EDP), EDV, end-systolic volume (ESV), end-systolic elastance, and stroke work after 8 weeks compared with untreated controls. Restraint also prevented infarct expansion while improving LV sphericity, cardiac output, and ejection fraction (EF). ${ }^{8}$ A later study of sheep with posterior infarcts confirmed improvements in LV sphericity and reductions in LV EDV after 8 weeks of therapy. ${ }^{9}$
Subsequent animal studies have modeled the more clinically relevant scenario in which the CorCap is not placed prophylactically, but rather after the development of ischemic CHF, induced by coronary microembolization in dogs or open surgical coronary ligation in sheep. These studies showed that 2 to 3 months of CorCap treatment not only prevents but also reverses the adverse changes seen in CHF, as demonstrated by reduced LV dilatation, ${ }^{4,10-15}$ improved LV $\mathrm{EF},{ }^{11-13}$ limited infarct expansion, ${ }^{16}$ preserved border zone function, ${ }^{16-18}$ and improved LV sphericity (LV length/LV width). ${ }^{14}$

Other benefits include decreased left atrial enlargement and improved left atrial function, ${ }^{\text {E12 }}$ as well as decreased severity of subsequent ischemic functional mitral regurgitation (FMR) when placed prophylactically. ${ }^{14,18}$ Restraint can also eliminate preexisting trace-to-mild mitral regurgitation (MR), ${ }^{10}$ but to date, no animal studies have demonstrated the more clinically relevant ability to reverse more severe grades of preexisting FMR.

Biochemical analysis. Animal studies of the CorCap have yielded insight into the mechanism of ventricular restraint at the cellular and molecular levels. Compared with untreated controls, 3 months of CorCap treatment in dogs with CHF decreased the expression of stretch response proteins, including $\mathrm{p} 21 \mathrm{ras}$, c-fos, and $\mathrm{p} 38 \alpha / \beta$ mitogenactivated protein kinase, suggesting that restraint can induce a global attenuation of the stretch response known to cause cardiomyocyte hypertrophy and subsequent adverse remodeling in CHF. ${ }^{\mathrm{E} 13}$ In addition, long-term CorCap treatment restores myocardial calcium cycling, resulting in improved contractility attributed ultimately to improved phosphorylation of sarcoplasmic reticulum $\mathrm{Ca}^{2}+$ ATPase, a calcium pump in the sarcoplasmic reticulum involved in the sequestration and release of calcium. $^{\text {E14 }}$

CorCap treatment also reverses maladaptive genetic changes associated with CHF. These effects include upregulation of $\alpha$-myosin heavy chain mRNA (associated with improved contractility) ${ }^{\mathrm{E} 15}$ and downregulation of mRNA for alpha and beta natriuretic peptides (high levels of which are associated with poor outcomes in CHF). ${ }^{\text {E16 }}$ CorCap treatment also upregulates mRNA expression of vascular endothelial growth factor and basic fibroblast growth factor, and downregulates several index matrix metalloproteinases (MMPs; eg, MMP-1, MMP-2, and MMP-9), normalizing these factors in animals with CHF. ${ }^{15, \text { E17,E18 }}$ Finally, CorCap treatment leads to reversal of myocardial collagen degradation, a maladaptive process occurring in CHF in which both the overall collagen content and the relative proportion of fibrillar collagen (type I) decrease. ${ }^{\text {E19,E20 }}$ Together, these effects are thought to produce myocardium that is less prone to infarct expansion and ventricular dilation. ${ }^{\text {E19,E20 }}$ 


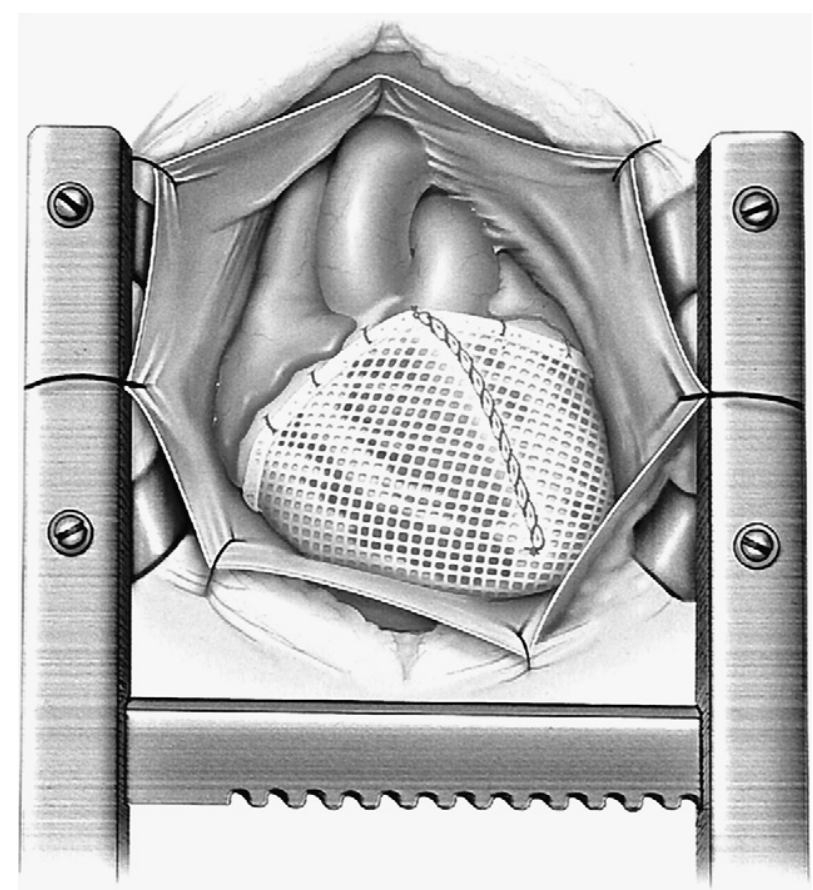

FIGURE 1. Acorn CorCap Cardiac Support Device (Acorn Cardiovascular Inc, St Paul, Minn). The device is attached at the atrioventricular groove using interrupted sutures. An anterior seam is used to create the proper device fit. Reprinted with permission. ${ }^{19}$

\section{Human Clinical Trials}

Initial safety studies. In 1999, initial safety studies of CorCap placement in 32 patients with New York Heart Association (NYHA) class II and III heart failure in Germany $(\mathrm{N}=27)$ and Australia $(\mathrm{N}=5)$ showed significant improvements in NYHA classification, reduced LV size, and no device-related morbidity. ${ }^{19,20}$ By 2002, pooled data from 48 patients worldwide, 33 of whom received concomitant cardiac surgery, corroborated these results,

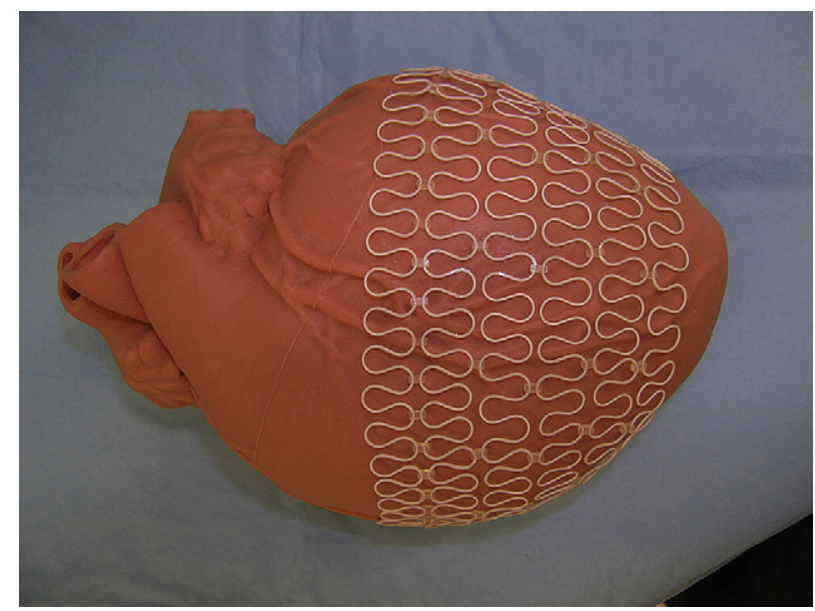

FIGURE 2. Paracor HeartNet device (Paracor Medical, Sunnyvale, Calif) implanted over a heart model. Reprinted with permission. ${ }^{27}$

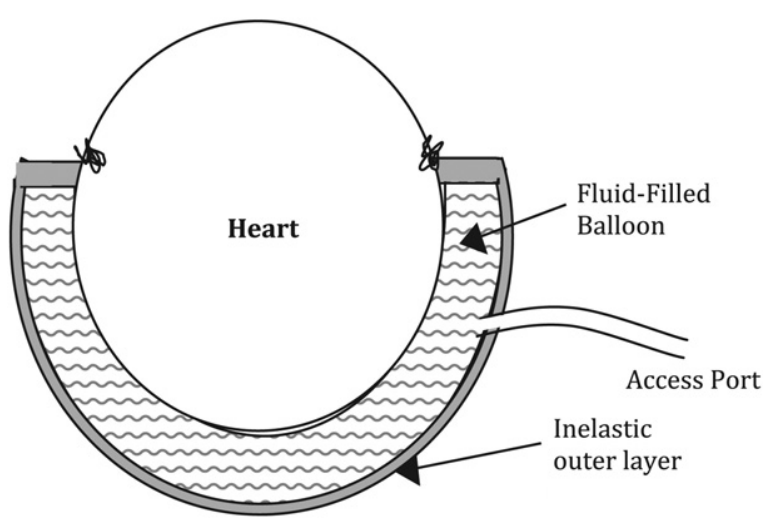

FIGURE 3. Quantitative ventricular restraint device. Schematic of a coronal section. Reprinted with permission. ${ }^{32}$

with no device-related intraoperative complications and a mean implantation time of 27 minutes. ${ }^{19}$ There were 8 early and 9 late deaths, none of which were device related, although 1 of the early deaths occurred after device placement alone without concomitant cardiac surgery. ${ }^{19}$ Both LV end-diastolic dimension (EDD) and EF improved as early as 3 months, with further improvements at 6 and 12 months (LV EDD reduction from 72.8 to $64.1 \mathrm{~mm}$, EF increase from $23.6 \%$ to $29.9 \%$ ) that were preserved at both $24^{19}$ and $36^{20}$ months. In addition, patients treated with the CorCap had substantial improvements in CHF symptoms and NYHA classification. ${ }^{19,20}$

Randomized clinical trials. The Acorn Trial began in 2004 as a randomized, controlled trial of 300 patients in 29 centers in the United States and Canada to evaluate the safety and efficacy of the CorCap in patients with CHF. ${ }^{21}$ In the nonmitral surgery stratum (107 patients), patients with CHF without significant MR were randomized to CorCap implant versus optimal medical therapy. In the mitral surgery stratum (193 patients), patients with CHF with MR were randomized to mitral valve replacement (MVR) or MVR with CorCap implantation to determine whether CorCap implantation added incremental value to MVR. ${ }^{22}$ The primary end point of the study was a clinical composite score based on survival, NYHA classification, and the need for major cardiac procedures.

Twelve months postoperatively, pooled analysis of both strata showed that CorCap treatment significantly reduced the need for major cardiac procedures (heart transplant, LVAD, mitral/tricuspid surgery) and improved NYHA functional status without any differences in device- or implantation-related deaths, serious adverse events, or hospitalizations. ${ }^{23}$ However, no survival advantage (or disadvantage) was seen in the treatment group. ${ }^{23}$ For secondary end points, there were significant reductions in the mean LV EDV ( $>30 \%$ reduction) and LV ESV ( $>25 \%$ reduction), and an increase in the mean LV sphericity index $(>0.06$ unit increase), but no differences in the mean LV 

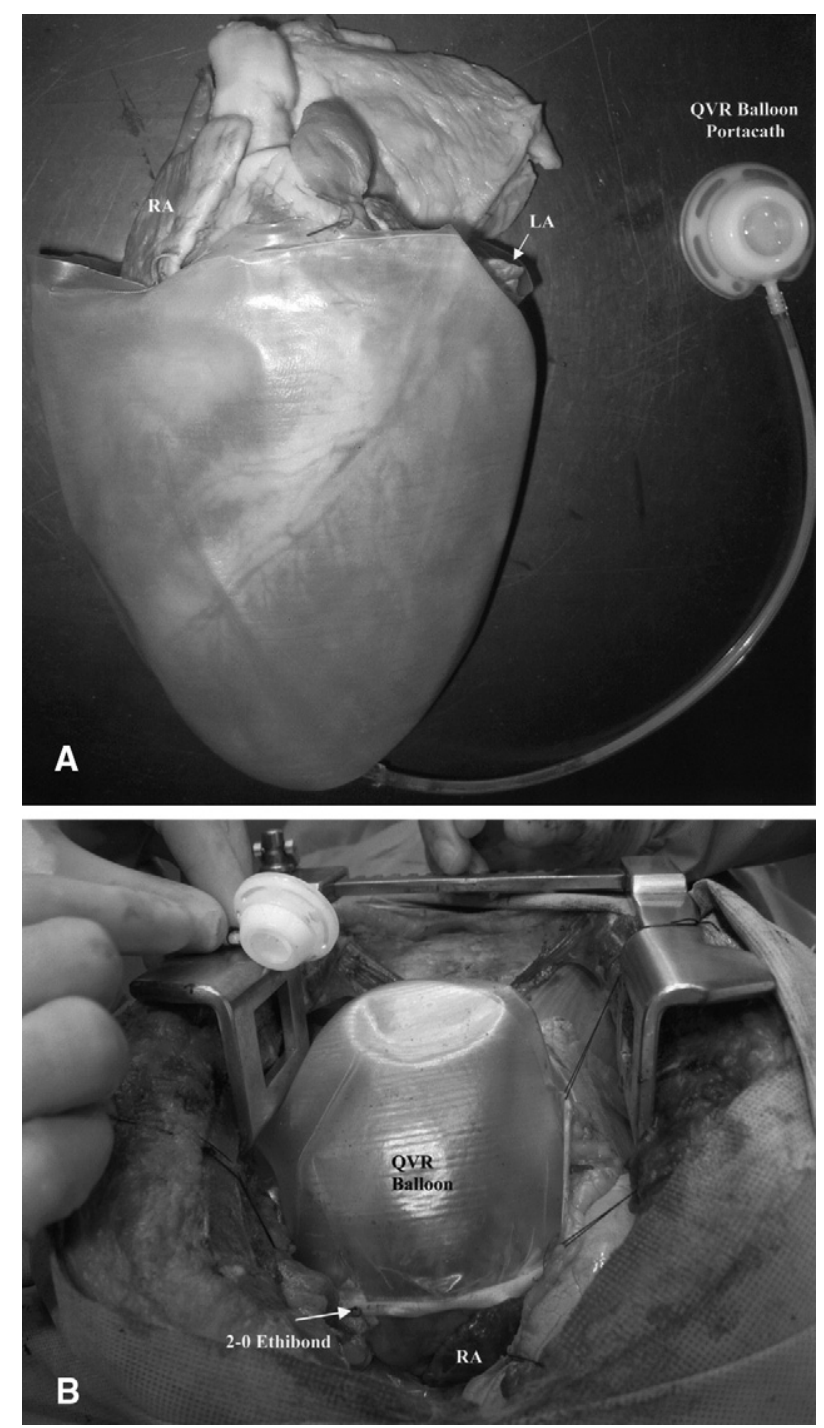

FIGURE 4. A, Photograph of half-ellipsoidal fluid-filled balloon for quantitative ventricular restraint $(Q V R)$. B, Intraoperative photograph of balloon implantation. Reprinted with permission. ${ }^{6} L A$, Left atrium; $R A$, right atrium.

EF at 12 months compared with controls. ${ }^{23}$ Thus, with the exception of the effect on the EF, the Acorn Trial confirmed nearly all of the positive effects of reverse ventricular remodeling and function seen in animal studies and initial safety trials. The primary and secondary end points were qualitatively maintained at $3^{24}$ and $5^{25}$ years of follow-up. Ultimately, however, the Food and Drug Administration did not approve the device primarily over concerns of safety (citing the $7.8 \%$ perioperative mortality in the non-MVR stratum) and efficacy. ${ }^{25}$ However, the lack of any survival disadvantage at 5 years may reinvigorate interest in this therapy clinically. ${ }^{25}$

Results from the MVR stratum were initially reported at 18 months and demonstrated an exceedingly low overall operative mortality of $1.6 \%$ at 30 days. ${ }^{22}$ Patients receiving MVR alone demonstrated progressive and significant decreases in LV EDV ( $\sim 50 \mathrm{~mL}$ decrease) and LV ESV ( $\sim 40 \mathrm{~mL}$ decrease), increases in EF (from $23.9 \%$ to $28.5 \%$ ) and sphericity index ( 0.116 unit increase), and dramatic improvements in mean MR grade (from 2.66 to 0.59). ${ }^{22}$ More important, however, the CorCap plus MVR group had further incremental improvements in LV EDV, LV ESV, and LV sphericity. ${ }^{22}$ Five-year results demonstrated a 75-mL reduction in the LV EDV in controls who underwent MVR alone, with an additional $16.5-\mathrm{mL}$ incremental reduction in those who also received CorCap placement. ${ }^{26}$ Neither the early nor late follow-up reports demonstrated any difference in the overall survival, frequency of recurrent MR, or rate of cardiac constriction. The impact on NYHA class was not reported, and only the earlier report describes an incremental improvement in quality of life as assessed by the Minnesota Living with Heart Failure Questionnaire. ${ }^{22}$

One important criticism of the entire Acorn Trial is the inclusion of the MVR stratum. This made the overall study somewhat difficult to understand conceptually, because recurrence of FMR is an intimately related but different outcome than reverse remodeling of heart failure. Further confusing the issue is that fact that only $6 \%$ of the patients in the MVR stratum had ischemic MR as the cause of the MR; ischemia, of course, is the primary cause of FMR in the general population. ${ }^{1, \mathrm{E} 21-\mathrm{E} 23}$ This criticism also applies to the non-MVR stratum, because most patients enrolled did not have ischemia as the primary cause. Thus, the results of the trial were criticized as being difficult to extrapolate to the more common ischemic general population with CHF.

The authors concluded that their data supported CorCap use for patients with nonischemic heart failure with moderate to severe LV dysfunction and significant MR despite medical optimization. ${ }^{26}$ In addition, the trial determined that patients with a preoperative LV EDD between 30 and $40 \mathrm{~mm} / \mathrm{m}^{2}$ of body surface area benefited most from the CorCap. $^{22}$ Above this level, CHF was considered too advanced to benefit from restraint; below this level, the ventricle was not dilated enough to justify invasive treatment with the CorCap. ${ }^{22,26}$ Ultimately, although CorCap placement results in sustained improvements in indices of $\mathrm{LV}$ remodeling in patients with moderate to severe largely nonischemic CHF, there are no major differences in survival or freedom from major cardiac events and no clear effect on symptoms or quality of life, leaving the overall efficacy of this specific application of ventricular restraint somewhat guarded in its current form.

\section{PARACOR HEARTNET}

The Paracor HeartNet (Figure 2) is the only other restraint device that has undergone human trials. It differs 
in 2 main respects from the CorCap. First, it is made of highly elastic Nitinol mesh and therefore exerts continuous elastic force on the heart throughout the cardiac cycle and not just at end-diastole. ${ }^{5}$ Second, although CorCap implantation requires median sternotomy and epicardial sutures, the HeartNet is implanted via left mini-thoracotomy using an introducer sheath and adheres to the heart by a textured inner surface. ${ }^{5}$

On the basis of evidence from a single prior animal study demonstrating the ability of the HeartNet device to attenuate LV EDV and ESV when placed immediately after infarct creation in sheep, ${ }^{5}$ initial clinical safety and feasibility studies were initiated and demonstrated low complication rates in 20 patients with nonischemic heart failure (NYHA class II and III) who received the device without other concomitant cardiac procedures. ${ }^{27}$ After this, a multi-institutional, nonrandomized, international study of 51 similar patients demonstrated favorable safety profiles with significant reductions in the LV EDD, LV EDV, and LV ESV, and significant improvements in the 6-minute walking test and the Minnesota Living with Heart Failure Questionnaire at 6 months. ${ }^{28}$ A randomized, controlled trial (Prospective Evaluation of Elastic Restraint to Lessen the Effects of Heart Failure [PEERLESS-HF]) was then conducted to compare HeartNet treatment with optimal medical therapy in 217 patients with NYHA class III CHF on stable medical regimens, LV EF $35 \%$ or less, LV EDD less than $85 \mathrm{~mm}$, and LV EDD index less than $40 \mathrm{~mm} / \mathrm{m}^{2} .{ }^{29}$ Despite showing significantly decreased LV EDD and LV ESD after 6 months of treatment, the trial was halted when no significant differences in $\mathrm{mVO}_{2}$ at 6 months or survival at 12 months were observed. ${ }^{29}$ No further clinical reports of the HeartNet device have since been published.

\section{QUANTITATIVE VENTRICULAR RESTRAINT}

Quantitative ventricular restraint (QVR) was developed to better understand the mechanics of restraint and thereby establish a means to optimize its benefits by overcoming the major limitations of prior devices, namely, the inability to measure and adjust the restraint level. With previous nonquantitative devices, the fundamental hypothesis that restraint ultimately leads to reverse remodeling by decreasing transmural myocardial pressure $\left(\mathrm{P}_{\mathrm{tm}}\right)$ and thereby $\mathrm{mVO}_{2}$ cannot be tested because epicardial pressures, required for obtaining $\mathrm{P}_{\mathrm{tm}}$, cannot be measured. In addition, because surgeons are instructed to implant current devices "snugly" around the heart, standardized methods for accurately establishing and adjusting wrap tightness do not exist. Once implanted, the wrap remains constant even as the heart reverse remodels and shrinks, causing the wrap to become effectively looser and redundant. Because the level of restraint may determine the degree of benefit and risk to the failing heart, our group perceived the nonadjustable and nonmeasurable nature of earlier devices as the biggest limitation to developing rational criteria to optimize therapy in a physiologic manner.

We therefore designed a QVR device that allows for both measurement and adjustment of the restraint level. The device itself is a flexible, inflatable, half-ellipsoidal polyurethane balloon that fits around both ventricles (Figures 3 and 4) and is connected to an airtight access line terminating in a subcutaneous port in the chest (Port-a-Cath; Bard Access Systems, Salt Lake City, Utah) through which the volume and pressure in the balloon can be adjusted and measured transcutaneously. Because the inner layer of the device is elastic and redundant, and the outer layer is inelastic, any fluid introduced into the balloon lumen has only one direction of filling, that is, toward the heart, thereby creating a tighter wrap. The $\mathrm{P}_{\mathrm{tm}}$ can be calculated using the balloon pressure, which is, by definition, equal to the epicardial pressure.

\section{Animal Studies}

We first determined the acute effects of varying the restraint level as defined by the balloon pressure at enddiastole, with the hypothesis that there is an optimal restraint level that maximizes the benefit to the heart without leading to tamponade. By using a postinfarction ovine model of CHF, we showed that QVR at a restraint level of $3 \mathrm{~mm} \mathrm{Hg}$ significantly reduced the LV $\mathrm{P}_{\mathrm{tm}}$ and markers of $\mathrm{mVO}_{2}$, including the tension-time index and pressurevolume area, without causing tamponade in the acute setting. ${ }^{6}$ Restraint levels of 5 and $8 \mathrm{~mm} \mathrm{Hg}$ led to cardiac tamponade, suggesting that $3 \mathrm{~mm} \mathrm{Hg}$ was the optimal restraint level. ${ }^{6}$ After 2 months of restraint at this optimal level, there were significant improvements in the LV EDV (30\% reduction from baseline) and the LV EF (60\% improvement from baseline, $24 \%$ higher than untreated controls). ${ }^{6}$ In addition, when normal hearts were compared with cardiomyopathic hearts, ventricular restraint decreased $\mathrm{LV} \mathrm{P}_{\mathrm{tm}}$, tensiontime index, and pressure-volume area equally at the restraint levels tested, demonstrating that LV size, preload, and contractility were not determinative factors in the reduction of $\mathrm{P}_{\mathrm{tm}}$ and $\mathrm{mVO}_{2}$, that is, the mechanical effect of restraint is determined primarily by wrap mechanics and not by the contractile or mechanical properties of the heart itself, thereby making standardization of QVR for patients possible. $^{6}$

We then investigated the feasibility of postoperatively measuring and adjusting the restraint level after QVR placement. ${ }^{30}$ After QVR implantation in 9 postinfarct sheep with CHF, restraint level was measured percutaneously after 2 days and adjusted back to the optimal restraint level of 3 $\mathrm{mm} \mathrm{Hg}$. In addition to documenting improvements in LV EDV and LV EF as early as 3 weeks postoperatively, this study demonstrated that it is technically feasible to postoperatively adjust and measure the effects of varying the restraint level acutely in real-time. 
By using the same ovine model of CHF, we then tested the effects of chronic restraint at varying restraint levels $(1.5$ and $3.0 \mathrm{~mm} \mathrm{Hg})$ and found that compared with the low restraint group, the high restraint group had significantly greater reductions in LV EDV (28\% reduction vs $18 \%$ reduction) and a trend toward greater improvements in LV EF (28\% to $44 \%$ vs $28 \%$ to $41 \%) .{ }^{31}$ In a second part of the same study, we compared chronic application of QVR at $3.0 \mathrm{~mm} \mathrm{Hg}$ (with biweekly adjustment of the restraint level back to $3.0 \mathrm{~mm} \mathrm{Hg}$ ) to standard, nonquantitative mesh wrap restraint and found that QVR demonstrated significantly greater reductions in LV EDV $(12.7 \%$ vs $5.7 \%$ reduction) and LV ESV $(20.6 \%$ vs $11.4 \%$ reduction), and a trend toward greater improvements in LV EF (18.9\% vs $14.4 \%$ increase). ${ }^{31}$ Of note, there were significant decreases in the measured restraint level as early as 2 weeks postoperatively, coincident with when LV EDV first began to decrease. This shows that early reverse remodeling does make the QVR device effectively looser and underscores the potential benefit of periodic readjustment to maximize efficacy. ${ }^{31}$

Finally, we tested the hypothesis that in standard QVR, in which a single level of restraint is applied to both ventricles, the pressure exerted on the right ventricle (RV) and not the LV accounts for the tamponade effect seen at higher restraint levels. In the LV, increases in the level of restraint up to $8 \mathrm{~mm}$ $\mathrm{Hg}$ led to beneficial decreases in $\mathrm{P}_{\mathrm{tm}}$ without any effect on $\mathrm{LV}$ diastolic compliance or LV EDP. ${ }^{32}$ Meanwhile, the same increases in restraint led to significant decreases in RV compliance and increases in RV EDP (both detrimental), but without any reduction in the $\mathrm{P}_{\mathrm{tm}} \cdot{ }^{32}$ In other words, the benefits of standard, biventricular QVR for left-sided heart failure lie solely with the effect of restraint on the LV, whereas the detrimental effects leading to tamponade lie solely with the effect on the RV. This has led to the hypothesis currently being tested that for LV failure, applying partial restraint (ie, restraint of the LV only while leaving the RV exposed) might allow higher levels of restraint to be applied without acutely causing tamponade, and that these higher restraint levels might also produce even greater chronic benefits.

\section{DISCUSSION}

Ventricular restraint studies during the last 15 years have clearly established that even nonquantitative restraint devices can induce reverse remodeling in CHF. However, despite encouraging clinical safety profiles, the efficacy of these devices, although durable over a period of up to 5 years as seen in the most recent reports, remains limited. Despite clear improvements in LV remodeling, there remains no proven benefit in terms of long-term ventricular function or survival. Furthermore, there seems to be a limit to the amount of reverse remodeling with the CorCap and HeartNet, neither of which are available commercially because of financial difficulties encountered after losing
Food and Drug Administration approval for clinical use and investigation.

Meanwhile, ongoing animal studies of QVR have demonstrated that both the acute and the chronic physiologic benefits of nonquantitative restraint can be significantly improved. In particular, QVR has demonstrated the fundamental principle that the ability to apply an accurately quantified level of restraint is important, because it determines the degree of acute benefit and risk to the heart. If the level of restraint is too high, tamponade ensues, but if the restraint level is too low, the benefits of restraint are not fully realized. As a consequence, there is an optimal restraint level that maximizes these acute benefits without subjecting the heart to restrictive physiology. Moreover, in addition to these acute differences, there is a restraint level-dependent response in the degree of remodeling and functional improvement in the chronic period as well, ${ }^{31}$ for which the differences in acute hemodynamics and energetics are likely responsible. Ultimately, candidates for optimized QVR would likely be similar to those in the Acorn Trial, that is, medically optimized patients who do not require LVAD support or transplant acutely, but whose CHF is symptomatic and associated with LV dilation sufficient to warrant restraint therapy.

Avenues that merit additional investigation include whether partial QVR for LV failure is superior to standard (biventricular) QVR, with the goal of maximizing benefit to the diseased LV while avoiding tamponade by leaving the nondiseased RV unrestrained. Others include the possibility that restraint can be an adjunct or alternative to mitral surgery in the setting of FMR, a condition for which significant controversy remains concerning the optimal method of surgical management. Finally, because most studies of restraint have focused on LV failure, it remains unknown whether partial RV restraint may be beneficial in the setting of isolated RV failure. Put more generally, varying combinations of RV and LV failure may warrant specific combinations and levels of restraint to most optimally benefit the heart.

\section{CONCLUSIONS}

Despite several major limitations to standard ventricular restraint therapy in its most recent nonquantitative clinical iteration, these limitations are largely a consequence of an incomplete physiologic understanding of the mechanism of restraint. As a new paradigm for ventricular restraint, QVR provides the ability to conduct rational investigation into the energetic and hemodynamic mechanisms that underlie its clinical benefit, and thereby the potential to realize another significant step toward optimizing ventricular restraint in a physiologic manner to maximize that benefit. Additional animal studies of QVR will be necessary to renew interest and rationale for initiating future human clinical studies of further optimized ventricular restraint. As 
restraint evolves in this manner, the hope is that there will be an epidemiologically significant improvement in clinical efficacy beyond what has been borne out in the currently available studies of standard restraint.

\section{References}

1. Lloyd-Jones DM, Adams R, Carnethon M, De Simone J, Ferguson TB, Flegal K, et al. Heart Disease and Stroke Statistics-2009 update. A report from the American Heart Association statistics committee and stroke statistics subcommittee. Circulation. 2009;119:480-6.

2. Kass DA, Baughman KL, Pak PH, Cho PW, Levin HR, Gardner TJ, et al. Reverse remodeling from cardiomyoplasty in human heart failure: external constraint versus active assist. Circulation. 1995;91:2314-8.

3. Capouya ER, Gerber RS, Drinkwater DC Jr, Pearl JM, Sack JB, Aharon AS, et al. Girdling effect of nonstimulated cardiomyoplasty on left ventricular function. Ann Thorac Surg. 1993;56:867-71.

4. Power JM, Raman J, Dornom A, Farish SJ, Burrell LM, Tonkin AM, et al. Passive ventricular constraint amends the course of heart failure: a study in an ovine model of dilated cardiomyopathy. Cardiovasc Res. 1999;44:549-55.

5. Magovern JA, Teekell-Taylor L, Mankad S, Dasika U, McGregor W, Biederman RW, et al. Effect of a flexible ventricular restraint device on cardiac remodeling after acute myocardial infarction. ASAIO J. 2006;52:196-200.

6. Ghanta RK, Rangaraj A, Umakanthan R, Lee L, Laurence RG, Fox JA, et al. Adjustable, physiological ventricular restraint improves left ventricular mechanics and reduces dilatation in an ovine model of chronic heart failure. Circulation. 2007;115:1201-10

7. Oz MC. Surgical implantation of the Acorn cardiac support device. Op Tech Thorac Cardiovasc Surg. 2002;7:107-10.

8. Kelley ST, Malekan R, Gorman JH III, Jackson BM, Gorman RC, Suzuki Y, et al. Restraining infarct expansion preserves left ventricular geometry and function after acute antero-apical infarction. Circulation. 1999;99:135-42.

9. Cheng A, Nguyen TC, Malinowski M, Langer F, Liang D, Daughters GT, et al. Passive ventricular constraint prevents transmural shear strain progression in left ventricle remodelling. Circulation. 2006;114(1 Suppl):I79-86.

10. Chaudhry PA, Mishima T, Sharov VG, Hawkins J, Alferness C, Paone G, et al. Passive epicardial containment prevents ventricular remodeling in heart failure. Ann Thorac Surg. 2000;70:1275-80.

11. Chaudhry PA, Anagostopouls PV, Mishima T, Suzuki G, Nair H, Morita H, et al. Acute ventricular reduction with the Acorn cardiac support device: effect on progressive left ventricular dysfunction and dilation in dogs with chronic heart failure. J Card Surg. 2001;16:118-26.

12. Sabbah HN, Sharov VG, Chaudhry PA, Suzuki G, Todor A, Morita H. Chronic therapy with the Acorn cardiac support device in dogs with chronic heart failure: three and six months hemodynamic, histologic and ultrastructural findings. $J$ Heart Lung Transplant. 2001;20:189.

13. Pilla JJ, Blom AS, Brockman DJ, Ferrari VA, Yuan Q, Acker MA. Passive ventricular constraint to improve left ventricular function and mechanics in an ovine model of heart failure secondary to acute myocardial infarction. J Thorac Cardiovasc Surg. 2003;126:1467-76.

14. Enomoto Y, Gorman JH III, Moainie SL, Jackson BM, Parish LM, Plappert T, et al. Early ventricular restraint after myocardial infarction: extent of the wrap determines the outcome of remodeling. Ann Thorac Surg. 2005;79:881-7.

15. Blom AS, Mukherjee R, Pilla JJ, Lowry AS, Yarbrough WM, Mingoia JT, et al. Cardiac support device modifies left ventricular geometry and myocardial structure after myocardial infarction. Circulation. 2005;112:1274-83.
16. Blom AS, Pilla JJ, Arkles J, Dougherty L, Ryan LP, Gorman JH III, et al. Ventricular restraint prevents infarct expansion and improves borderzone function af ter myocardial infarction: a study using magnetic resonance imaging, three-dimensional surface modeling, and myocardial tagging. Ann Thorac Surg. 2007;84:2004-10.

17. Pilla JJ, Blom AS, Gorman JH III, Brockman DJ, Affuso J, Parish LM, et al. Early postinfarction ventricular restraint improves borderzone wall thickening dynamics during remodeling. Ann Thorac Surg. 2005;80:2257-62.

18. Moainie SL, Guy TS, Gorman JH III, Plappert T, Jackson BM, JohnSutton MG, et al. Infarct restraint attenuates remodeling and reduces chronic ischemic mitral regurgitation after postero-lateral infarction. Ann Thorac Surg. 2002;74:444-9.

19. Oz MC, Konertz WF, Kleber FX, Mohr FW, Gummert JF, Ostermeyer J, et al Global surgical experience with the Acorn cardiac support device. J Thorac Cardiovasc Surg. 2003;126:983-91.

20. Starling RC, Jessup M. Worldwide clinical experience with the CorCap cardiac support device. J Card Fail. 2004;10:S225-33.

21. Mann DL, Acker MA, Jessup M, Sabbah HN, Starling RC, Kubo SH, et al. Rationale, design, and methods for a pivotal randomized clinical trial for the assessment of a cardiac support device in patients with New York health association class III-IV heart failure. J Card Fail. 2004;10:185-92.

22. Acker MA, Bolling S, Shemin R, Kirklin J, Oh JK, Mann DL, et al. Mitral valve surgery in heart failure: insights from the Acorn Clinical Trial. J Thorac Cardiovasc Surg. 2006;132:568-77, 577.e1-4.

23. Mann DL, Acker MA, Jessup M, Sabbah HN, Starling RC, Kubo SH, et al. Clinical evaluation of the CorCap Cardiac Support Device in patients with dilated cardiomyopathy. Ann Thorac Surg. 2007;84:1226-35.

24. Starling RC, Jessup M, Oh JK, Sabbah HN, Acker MA, Mann DL, et al. Sustained benefits of the Corcap cardiac support device on left ventricular remodeling: three year follow-up results from the Acorn clinical trial. Ann Thorac Surg. 2007;84:1236-42.

25. Mann DL, Kubo SH, Sabbah HN, Starling RC, Jessup M, Oh JK, et al. Beneficial effects of the CorCap cardiac support device: five-year results from the Acorn Trial. J Thorac Cardiovasc Surg. 2012;143:1036-42.

26. Acker MA, Jessup M, Bolling SF, Oh J, Starling RC, Mann DL, et al. Mitral valve repair in heart failure: five-year follow-up from the mitral valve replacement stratum of the Acorn randomized trial. Cardiovasc Surg. 2011;142:569-74.

27. Klodell CT Jr, McGiffin DC, Rayburn BK, Sun B, Abraham WT, Conte JV, et al Initial United States experience with the Paracor HeartNet myocardial constraint device for heart failure. J Thorac Cardiovasc Surg. 2007;133:204-9.

28. Klodell CT Jr, Aranda JM Jr, McGiffin DC, Rayburn BK, Sun B, Abraham WT, et al. Worldwide surgical experience with the Paracor HeartNet cardiac restraint device. J Thorac Cardiovasc Surg. 2008;135:188-95.

29. Abraham WT. Ventricular elastic support therapy (VEST) in stage C heart failure: analysis from the PEERLESS-HF study. Heart Failure Society of America 2010 Scientific Meeting, September 13, 2010, San Diego, CA. Late-breaking clinical trial 1.

30. Ghanta RK, Lee LS, Umakanthan R, Laurence RG, Fox JA, Bolman RM III, et al. Real-time adjustment of ventricular restraint therapy in heart failure. Eur J Cardiothorac Surg. 2008;34:1136-40.

31. Lee LS, Ghanta RK, Mokashi SA, Coelho-Filho O, Kwong RY, Kwon M, et al Optimized ventricular restraint therapy: adjustable restraint is superior to standard restraint in ischemic cardiomyopathy. J Thorac Cardiovasc Surg. June 12, 2012 [epub ahead of print].

32. Lee LS, Ghanta RK, Mokashi SA, Coelho-Filho O, Kwong RY, Bolman RM III et al. Ventricular restraint therapy for heart failure: the right ventricle is different than the left ventricle. J Thorac Cardiovasc Surg. 2010;139:1012-8. 


\section{E-References}

E1. Jones RH, Velazquez EJ, Michler RE, Sopko G, Oh JK, O'Connor CM, et al. Coronary bypass surgery with or without surgical ventricular reconstruction. N Engl J Med. 2009;360:1705-17.

E2. Franco-Cereceda A, McCarthy PM, Blackstone EH, Hoercher KJ, White JA, Young JB, et al. Partial left ventriculectomy for dilated cardiomyopathy: is this an alternative to transplantation? J Thorac Cardiovasc Surg. 2001;121: 879-93.

E3. Mark DB, Knight JD, Velazquez EJ, Howlett JG, Spertus JA, Djokovic LT, et al. Quality of life and economic outcomes with surgical ventricular reconstruction in ischemic heart failure: results from the Surgical Treatment for Ischemic Heart Failure trial. Am Heart J. 2009;157:837-44, 844.e1-3.

E4. Weston MW, Vijayangar R, Overton RM, Veseley DL. Prospective evaluation of the Batista procedure with circulating atrial natriuretic peptides. Int J Cardiol. 2000;74:145-52.

E5. McCarthy PM, Takagaki M, Ochiai Y, Young JB, Tabata T, Shiota T, et al. Device-based change in left ventricular shape: a new concept for the treatment of dilated cardiomyopathy. J Thorac Cardiovasc Surg. 2001;122: 482-90.

E6. Slaughter MS, Meyer AL, Birks EJ. Destination therapy with left ventricular assist devices: patient selection and outcomes. Curr Opin Cardiol. 2011;26: 232-56.

E7. Aggarwal S, Pagani FD. Bridge to transplantation: current outcomes. J Card Surg. 2010;25:455-61.

E8. John R, Liao K, Lietz K, Kamdar F, Colvin-Adams M, Boyle A, et al. Experience with the Levitronix CentriMag circulatory support system as a bridge to decision in patients with refractory acute cardiogenic shock and multisystem organ failure. J Thorac Cardiovasc Surg. 2007;134:351-8.

E9. Birks EJ, Tansley PD, Hardy J, George RS, Bowles CT, Burke M, et al. Left ventricular assist device and drug therapy for the reversal of heart failure. $N$ Engl J Med. 2006;355:1873-84

E10. Anstadt MP, Budharaju S, Darner RJ, Schmitt BA, Prochaska LJ, Pothoulakis AJ, et al. Ventricular actuation improves systolic and diastolic myocardial function in the small failing heart. Ann Thorac Surg. 2009;88: 1982-8.

E11. Chachques JC, Jegaden O, Mesana T, Glock Y, Grandjean PA, Carpentier AF, et al. Cardiac bioassist: results of the French multicenter cardiomyoplasty study. Asian Cardiovasc Thorac Ann. 2009;17:573-80.

E12. Zacà V, Brewer R, Khanal S, Imai M, Jiang $\mathrm{A}$, Wang $\mathrm{M}$, et al. Left atrial reverse remodeling in dogs with moderate and advanced heart failure treated with a passive mechanical containment device: an echocardiographic study. $J$ Card Fail. 2007;13:312-7.

E13. Sabbah HN, Sharov VG, Gupta RC, Mishra S, Rastogi S, et al. Reversal of chronic molecular and cellular abnormalities due to heart failure by passive mechanical ventricular containment. Circ Res. 2003;93:1095-101. Epub 2003 Oct 16.

E14. Sabbah HN. Effects of cardiac support device on reverse remodeling: molecular, biochemical, and structural mechanisms. J Card Fail. 2004;10(6 Suppl): S207-14.

E15. Gupta RC, Mishra S, Rastogi S, Sharov VG, Sabbah HN. Improvement of cardiac sarcoplasmic reticulum calcium cycling in dogs with heart failure following long-term therapy with the Acorn Cardiac Support Device. Heart Fail Rev. 2005; 10:149-55.

E16. Rastogi S, Mishra S, Gupta RC, Sabbah HN. Reversal of maladaptive gene program in left ventricular myocardium of dogs with heart failure following longterm therapy with the Acorn Cardiac Support Device. Heart Fail Rev. 2005;10: 157-63.

E17. Bowen FW, Jones SC, Narula N, St. John Sutton MG, Plappert T, Edmunds LH Jr, et al. Restraining acute infarct expansion decreases collagenase activity in borderzone myocardium. Ann Thorac Surg. 2001;72: 1950-6.

E18. Rastogi S, Gupta RC, Mishra S, Morita H, Tanhehco EJ, Sabbah HN. Longterm therapy with the Acorn cardiac support device normalizes gene expression of growth factors and gelatinases in dogs with heart failure. J Heart Lung Transplant. 2005;24:1619-25.

E19. Sharov VG, Todor AV, Sabbah HN. Left ventricular histomorphometric findings in dogs with heart failure treated with the Acorn Cardiac Support Device. Heart Fail Rev. 2005;10:141-7.

E20. Schroder JN, Lima B, Rogers JG, Milano CA. Cardiac transplantation following ACORN CorCap device implantation. Eur J Cardiothorac Surg. 2006;29: 848-50. Epub 2006 Apr 4.

E21. Perez de Isla L, Zamorano J, Quezada M, Almería C, Rodrigo JL, Serra V, et al. Prognostic significance of function mitral regurgitation after a first non-SET-segment elevation acute coronary syndrome. Eur Heart J. 2006; 27:2655-60

E22. Barzilai B, Davis VG, Stone PH, Jaffe AS. Prognostic significance of mitral regurgitation in acute myocardial infarction. The MILIS Study Group. Am J Cardiol. 1990;65:1169-75.

E23. Ngaage DL, Schaff HV. Mitral valve surgery in non-ischemic cardiomyopathy. J Cardiovasc Surg. 2004;45:477. 